\title{
Neurokinin 1 Receptors Regulate Morphine-Induced Endocytosis and Desensitization of $\mu$-Opioid Receptors in CNS Neurons
}

\author{
Y. Joy Yu, ${ }^{1}$ Seksiri Arttamangkul, ${ }^{3}$ Christopher J. Evans, ${ }^{4}$ John T. Williams, ${ }^{3}$ and Mark von Zastrow ${ }^{1,2}$ \\ ${ }^{1}$ Program in Neuroscience and ${ }^{2}$ Department of Psychiatry and Cellular and Molecular Pharmacology, University of California at San Francisco, San \\ Francisco, California 94158, ${ }^{3}$ Vollum Institute, Oregon Health \& Science University, Portland, Oregon 97239, and ${ }^{4}$ Department of Psychiatry and \\ Biobehavioral Sciences, University of California, Los Angeles, Los Angeles, California 90024
}

\begin{abstract}
$\mu$-Opioid receptors (MORs) are G-protein-coupled receptors (GPCRs) that mediate the physiological effects of endogenous opioid neuropeptides and opiate drugs such as morphine. MORs are coexpressed with neurokinin 1 receptors (NK1Rs) in several regions of the CNS that control opioid dependence and reward. NK1R activation affects opioid reward specifically, however, and the cellular basis for this specificity is unknown. We found that ligand-induced activation of NK1 Rs produces a cell-autonomous and nonreciprocal inhibition of MOR endocytosis induced by diverse opioids. Studies using epitope-tagged receptors expressed in cultured striatal neurons and a neuroblastoma cell model indicated that this heterologous regulation is mediated by NK1R-dependent sequestration of arrestins on endosome membranes. First, endocytic inhibition mediated by wild-type NK1Rs was overcome in cells overexpressing $\beta$-arrestin2, a major arrestin isoform expressed in striatum. Second, NK1R activation promoted sequestration of $\beta$-arrestin 2 on endosomes, whereas MOR activation did not. Third, heterologous inhibition of MOR endocytosis was prevented by mutational disruption of $\beta$-arrestin2 sequestration by NK1Rs. NK1R-mediated regulation of MOR trafficking was associated with reduced opioid-induced desensitization of adenylyl cyclase signaling in striatal neurons. Furthermore, heterologous regulation of MOR trafficking was observed in both amygdala and locus ceruleus neurons that naturally coexpress these receptors. These results identify a cell-autonomous mechanism that may underlie the highly specific effects of NK1R on opioid signaling and suggest, more generally, that receptor-specific trafficking of arrestins may represent a fundamental mechanism for coordinating distinct GPCR-mediated signals at the level of individual CNS neurons.
\end{abstract}

Key words: trafficking; opioid; arrestin; morphine; endocytosis; neurokinin

\section{Introduction}

G-protein coupled receptors (GPCRs) mediate a wide variety of physiological functions and are the targets of a vast array of both therapeutic and abused drugs. Opioid receptors comprise a subfamily of GPCRs that are activated both by endogenously produced opioid neuropeptides and exogenous alkaloid drugs such as morphine (Evans, 2000). The $\mu$-opioid receptor (MOR) is the primary target mediating analgesic, euphoric, and reinforcing effects of morphine (Matthes et al., 1996). After exposure to opioid peptides, MOR is phosphorylated and associates with $\beta$-arrestin (also called nonvisual arrestin), which modulates opioid signaling and functions as an adaptor protein to promote MOR endocytosis via clathrin-coated pits (Keith et al., 1996;

\footnotetext{
Received Sept. 9, 2008; revised 0ct. 29, 2008; accepted Nov. $28,2008$.

This work was supported by research grants from the National Institutes of Health (NIH). Y.J.Y. received support from a Gallo Predoctoral Fellowship in Alcohol and Addiction Studies and an NIH predoctoral fellowship (F31DA024530-01). We thank Nigel Bunnett and Marc Caron for valuable discussion and reagents and James Hislop for critical comments on this manuscript.

Correspondence should be addressed to Mark von Zastrow, Room N212 Genentech Hall, University of California at San Francisco Mission Bay Campus, 600 16th Street, San Francisco, CA 94158-2140. E-mail: mark.vonzastrow@ucsf.edu.

DOI:10.1523/JNEUROSCI.4315-08.2009

Copyright $\odot 2009$ Society for Neuroscience $\quad$ 0270-6474/09/290222-12\$15.00/0
}

Whistler and von Zastrow, 1998; Zhang et al., 1998; Oakley et al. 1999). This series of events is thought to contribute fundamentally to controlling MOR-mediated signaling under conditions of prolonged or repeated ligand exposure (Koch et al., 1998; Qiu et al., 2003). While morphine promotes relatively little regulated endocytosis of MOR compared with opioid peptides in several cell models, it does strongly produce endocytosis in striatal neurons, a brain region important for reward processing (Heimer et al., 1982; Keith et al., 1998; Whistler et al., 1999; Bushell et al., 2002; Haberstock-Debic et al., 2003, 2005; Trafton and Basbaum, 2004). Therefore, regulated endocytosis of MOR may play an important role in the actions of endogenous MOR in response to both peptides and drugs such as morphine.

Whereas MORs are major direct targets receptors of opiate drug action, various other GPCRs modulate opioid function in vivo. Of these, the neurokinin 1 receptor (NK1R) has been found to modulate MOR-dependent responses with a remarkably high degree of specificity. Mice lacking NK1Rs are insensitive to the rewarding properties of morphine, while the rewarding effects of food and cocaine are preserved (Murtra et al., 2000; Ripley et al., 2002). The antinociceptive effects of morphine remain intact in NK1R knock-out animals, further supporting the specificity of NK1R function in modulating opiate reward (De Felipe et al., 
1998). Moreover, MORs and NK1Rs are highly expressed in several brain regions relevant to reward processing, including the ventral striatum and amygdala (Pickel et al., 2000; Gadd et al., 2003; Nakaya et al., 1994; Jabourian et al., 2005; Poulin et al., 2006).

Given the known physiological interaction between the neurokinin and opioid neurochemical systems, and the coexpression of NK1R and MOR in relevant brain regions, we considered the possibility that these distinct receptor systems might interact functionally at the level of individual neurons. In the present study, we investigated this hypothesis in several cell populations, using both recombinant and natively expressed receptors. Our results identify a cell-autonomous mechanism by which NK1Rs specifically modulate MOR trafficking and signaling, and also suggest a more general principle of heterologous regulation of diverse GPCRs in the CNS.

\section{Materials and Methods}

\section{Plasmid DNA and mutagenesis}

The N-terminally FLAG (DYKDDDD) epitope-tagged murine $\mu$-opioid receptor (F-MOR) was described previously (Keith et al., 1996). The rat NK1 neurokinin receptor (cDNA generously provided by Dr. Nigel Bunnett, University of California, San Francisco, San Francisco, CA) was tagged in its $\mathrm{N}$-terminal extracellular domain with an HA (YPYDVPDYA) epitope-tag using PCR (HA-NK1R). Truncation at residue 355 was accomplished by introducing a stop codon using PCR (HA-NK1$355 x$ ). Tagged receptor constructs were cloned into pCAGGS (Niwa et al., 1991) for expression in cultured neurons, and pcDNA3.1 (Invitrogen) for expression in neuroblastoma 2 A cells (N2A). A bovine arrestin 3 ( $\beta$-arrestin2) construct, tagged with EGFP as described previously (Mundell and Benovic, 2000), was generously provided by Dr. J. Benovic (Thomas Jefferson University, Philadelphia, PA). All constructs were confirmed by DNA sequencing (Elim Biopharmaceuticals).

\section{Cell cultures and transfections}

Primary striatal neurons and primary amygdala neurons were dissected from embryonic day 17-18 rat embryos taken from pregnant Sprague Dawley rats. The striatum (caudate-putamen and nucleus accumbens) were dissected based on the criteria of Ventimiglia and Lindsay (1998). The amygdala was identified as described by Altman and Bayer (1995). Dissected tissue was dissociated in $1 \times$ trypsin/EDTA solution (Invitrogen) for $15 \mathrm{~min}$ before $1 \mathrm{ml}$ of trypsin inhibitor was added for $5 \mathrm{~min}$ at room temperature. Cells were washed and triturated in DMEM plus $10 \%$ fetal calf serum (FCS; Invitrogen). Mechanical trituration of tissue was performed using a glass pipette. Neuronal transfections were performed using electroporation (rat neuron nucleofector system; Amaxa Biosystems) immediately after dissociation and plated on poly-L-lysine-coated ( $1 \mathrm{mg} / \mathrm{ml}$ in $0.1 \mathrm{M}$ sodium borate buffer, $\mathrm{pH} 8.5$ ) glass coverslips washed previously in $70 \%$ nitric acid and rinsed over $2-3$ d. Electroporation was conducted using $5 \times 10^{6}$ dissociated cells, $3 \mu \mathrm{g}$ of plasmid DNA, and 100 $\mu \mathrm{l}$ of rat neuron nucleofector solution. After transfection, neurons were kept in prewarmed RPMI media (Cell culture facility, University of California San Francisco, San Francisco, CA) for 10 min for recovery before being transferred onto 24-well plates. Media on the cells was replaced with Gibco Neurobasal media (Invitrogen) supplemented with B27 (Gibco) and L-glutamine $24 \mathrm{~h}$ after transfection. Neurons were maintained $7-10 \mathrm{~d}$ in culture before assaying.

Neuroblastoma 2A cells were obtained from University of San Francisco cell culture facility and maintained in Gibco DMEM (Invitrogen) media supplemented with 10\% FCS and penicillin/streptomycin. Cells were plated on poly-D-lysine-coated $(50 \mu \mathrm{g} / \mathrm{ml}$ in water) glass coverslips onto 24-well plates for immunocytochemistry and $6 \mathrm{~cm}$ dishes for biotinylation assays. Transfections were performed using a cationic lipid transfection reagent (Effectene; Qiagen). Cells were transfected when they were at $50 \%$ confluency and assayed $24 \mathrm{~h}$ after transfection.

Immunocytochemistry and quantitative analysis of FLAG-MOR internalization. F-MOR and HA-NK1R distribution was visualized after dual immunocytochemical labeling with antibodies recognizing the distinct epitope tags. Rabbit anti-FLAG polyclonal antibody $(0.2 \mu \mathrm{g} / \mathrm{ml}$; Sigma $)$ and mouse anti-HA ( $5 \mu \mathrm{g} / \mathrm{ml}$; Covance) antibodies were added to the culture medium of transfected cells, and surface labeling was performed for $30 \mathrm{~min}$ before an additional $30 \mathrm{~min}$ incubation in the presence or absence of the indicated ligand(s). After quick washes with either TBS (for neurons) or PBS (for N2A cells), cells were fixed with $4 \%$ paraformaldehyde dissolved in $\mathrm{Ca}^{2+}$-free PBS supplemented with 5\% sucrose for $15 \mathrm{~min}$. Specimens were permeabilized and blocked for $20 \mathrm{~min}$ in a solution containing either $0.1 \%$ saponin (for neurons) or $0.1 \%$ Triton X-100 (for N2A cells), and 2\% BSA dissolved in the appropriate buffered saline. Secondary labeling was performed using Alexa594 goat antirabbit IgG (for F-MOR) and Alexa488 donkey anti-mouse IgG (for HANK1R) antibodies ( $2 \mu \mathrm{g} / \mathrm{ml}$; Invitrogen), prepared in the same blocking solution and incubated for $30 \mathrm{~min}$. Cells were then washed extensively with the appropriate buffered saline and mounted onto glass slides for fluorescence microscopy. Epifluorescence microscopy was performed using a Nikon Diaphot microscope equipped with a $60 \times /$ numerical aperture (NA) 1.4 objective, mercury arc lamp illumination and standard dichroic filter sets (Omega Optical). Images were collected with a CCD camera (Princeton Instruments) and analyzed using MetaMorph software (Molecular Devices). Confocal microscopy was performed with a Zeiss LSM510 instrument, equipped with a $63 \times /$ NA 1.4 objective and using a pinhole diameter of 1 Airy disc.

To quantify ligand effects observed with epifluorescence microscopy, we used a previously described assay to assess ratiometric staining of surface and internalized receptors (Haberstock-Debic et al., 2005). In brief, cells were incubated with Alexa594-conjugated M1 anti-FLAG monoclonal antibody $(5 \mu \mathrm{g} / \mathrm{ml}$ ) for $30 \mathrm{~min}$ (to selectively label F-MOR present in the plasma membrane) and then incubated in the absence or presence of the indicated ligand(s) for an additional $30 \mathrm{~min}$. Cells were fixed and incubated with Alexa488-conjugated donkey anti-mouse IgG for $30 \mathrm{~min}$ under nonpermeabilized conditions (2\% BSA in TBS) to selectively detect only those labeled F-MORs remaining at the plasma membrane. Therefore, internalized receptors were labeled with only Alexa594, while surface F-MORs were labeled with both Alexa594 and Alexa488. The percentage of receptor internalization induced by the indicated agonist exposure was calculated from background-subtracted Alexa594 (red) and Alexa488 (green) fluorescence intensity values according to the following formula: percentage internalized $=[1-($ green/ red ratio in agonist treated) $/($ green $/$ red ratio in untreated $)] \times 100$. For each experiment, 50 neuronal cell bodies or N2A cells were analyzed per condition. Results were compiled from five experiments for each cell type (and four for the N2A truncated HA-NK1R experiments). For experiments in primary cultures, these represented separate animals and culture preparations. Statistical analysis of differences between experimental groups was performed using unpaired Student's $t$ test.

Colocalization of receptors with $\beta$-arrestin2-EGFP. Colocalization of HA-NK1R and HA-NK1 355x with $\beta$-arrestin2-EGFP (in both localization and overexpression experiments) was obtained through a similar staining protocol as described above, except that rat anti-HA $(5 \mu \mathrm{g} / \mathrm{ml}$; Roche) was used as primary antibody and Alexa594-conjugated anti-rat IgG was used as secondary antibody. Triple localization of F-MOR, HANK1R, and $\beta$-arrestin2-EGFP was performed using Alexa594 conjugated to M1 anti-FLAG and rat anti-HA primary antibodies, and HA-NK1R was visualized with Alexa647 goat anti-rat secondary antibody. Cells were imaged using the same confocal microscopy settings as described above. For colocalization experiments, control imaging of single-labeled cells was performed to confirm lack of detectable bleed through between channels.

Immunocytochemistry analysis of endogenous receptors. For immunocytochemical localization of endogenous receptors, cultured amygdala neurons (grown $\sim 7 \mathrm{~d}$ in culture on poly-L-lysine-coated glass coverslips) were incubated with the indicated ligand(s) for 30 min followed by a 10 min fixation in ice-cold methanol. Cells were blocked in PBS containing $5 \%$ goat serum, $0.3 \%$ Tween 20 , and $0.1 \%$ Triton X-100 in PBS for 45 min. Staining for endogenous MOR and NK1R was performed using an affinity-purified rabbit antibody recognizing the $\mathrm{C}$ terminus of MOR1 (Keith et al., 1998) and a guinea pig antibody recognizing the distinct $\mathrm{C}$ terminus of NK1R (1:5000; AB15810, Millipore), respectively. Perme- 
abilized specimens were coincubated with both antibodies at $25^{\circ} \mathrm{C}$ for $2.5 \mathrm{~h}$ and then extensively washed in PBS after primary incubation. Localization of receptors was visualized after secondary labeling with Alexa594-conjugated goat anti-rabbit IgG (for F-MOR) and Alexa488conjugated donkey anti-mouse IgG (for HANK1R) antibodies (2 $\mu \mathrm{g} / \mathrm{ml}$; Invitrogen) prepared in the same blocking solution as above and incubated for $60 \mathrm{~min}$.

\section{Receptor internalization with surface biotinylation and immunoblotting}

N2A cells were grown to $50 \%$ confluency on 6 $\mathrm{cm}$ dishes and transfected with F-MOR and HA-NK1R, or F-MOR and the truncated HANK1R (HA-NK1 355x). Transfected cells were washed with cold $\mathrm{Ca}^{2+}$ - and $\mathrm{Mg}^{2+}$-free PBS and then incubated in $0.3 \mathrm{mg} / \mathrm{ml}$ Sulfo-NHSSS-biotin (Pierce) in PBS at $4^{\circ} \mathrm{C}$ for $20 \mathrm{~min}$. Cells were washed with TBS and placed in DMEM for $10 \mathrm{~min}$ at $37^{\circ} \mathrm{C}$ before incubation for $30 \mathrm{~min}$ under the indicated conditions. Cells were then washed on ice with TBS, to remove and quench residual biotinylation reagent, and remaining cell surface biotinylated receptors were stripped at $4^{\circ} \mathrm{C}$ two times for 15 min each using $100 \mathrm{~mm}$ MESNA (Sigma-Aldrich) in 50 mM Tris 8.8, $100 \mathrm{~mm} \mathrm{NaCl}, 1 \mathrm{~mm}$ EDTA, and $0.2 \%$ BSA. Stripped cells were then quenched with iodoacetamide buffer $(22 \mathrm{mg} / \mathrm{ml}$ iodoacetamide in TBS) for $10 \mathrm{~min}$ at $4^{\circ} \mathrm{C}$. Cells were extracted with lysis buffer containing $1 \mathrm{mg} / \mathrm{ml}$ iodoacetamide in IP buffer $(0.2 \%$ Triton X-100, $150 \mathrm{~mm} \mathrm{NaCl}, 25 \mathrm{~mm} \mathrm{KCl}, 10 \mathrm{~mm}$ Tris 7.4) supplemented with $0.1 \mathrm{~mm}$ EDTA and a Complete mini EDTA-free protease inhibitor cocktail tablet ( 1 tablet/10 ml; Roche). Cell debris was removed by centrifugation at $13,000 \times g$ for 15 min at $4^{\circ} \mathrm{C}$. Extracts containing equal amounts of cellular protein (determined using Coomassie Plus protein assay from Pierce) were incubated with immobilized streptavidin beads (Pierce) on a rotator overnight at $4^{\circ} \mathrm{C}$. Proteinbound streptavidin beads were centrifuged at $3000 \times g$ for $1 \mathrm{~min}$ at $4^{\circ} \mathrm{C}$ and washed twice with IP buffer. Proteins were eluted and denatured in SDS sample buffer with $10 \% \beta$-mercaptoethanol and separated by SDS/PAGE. Proteins were transferred to nitrocellulose and biotinylated proteins were detected by immunoblotting with anti-FLAG M1 mouse antibody ( $5 \mu \mathrm{g} / \mathrm{ml}$; Sigma) followed by anti-mouse IgG horseradish peroxidase conjugate (1:5000, Amersham) and chemiluminescence detection using ECL reagent (Amersham).

\section{Determination of receptor signaling by measurement of} cAMP accumulation

Dissociated striatal neurons were cotransfected with F-MOR and HANK1R and maintained for 7-10 d in culture before assaying. Before agonist treatment, neurons were incubated in media containing the phosphodiesterase inhibitor 3-isobutyl-1-methylxanthine (IBMX, Sigma) at a concentration of $1 \mathrm{~mm}$. To assess acute signaling response, neurons were exposed for $3 \mathrm{~min}$ to $3 \mu \mathrm{M}$ forskolin and $1 \mathrm{mM}$ IBMX, in the presence $10 \mu \mathrm{M}$ morphine, $10 \mu \mathrm{M}$ substance $\mathrm{P}$, or both. To assess MOR desensitization, neurons were preincubated in the presence morphine, substance $\mathrm{P}$ or both for $30 \mathrm{~min}$. The indicated agonists were then washed out and the ability of neurons to subsequently respond to opiate was assessed by rechallenge for $10 \mathrm{~min}$ with $100 \mathrm{nM}$ morphine in the presence of $3 \mu \mathrm{M}$ forskolin and $1 \mathrm{mM}$ IBMX. After agonist incubations, cells were immediately washed once with ice-cold PBS before lysing in $0.1 \mathrm{M} \mathrm{HCl}$ with $0.1 \%$ Triton X-100. Lysates were collected and particulates removed by

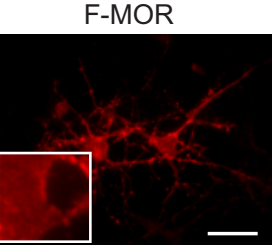

HA-NK1R
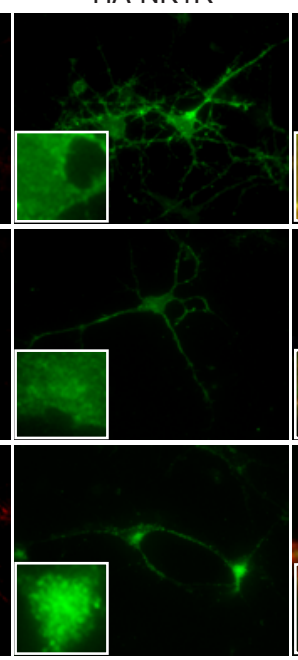

P.

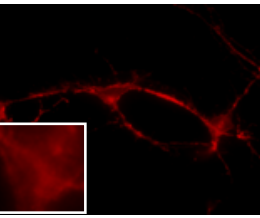

F-MOR
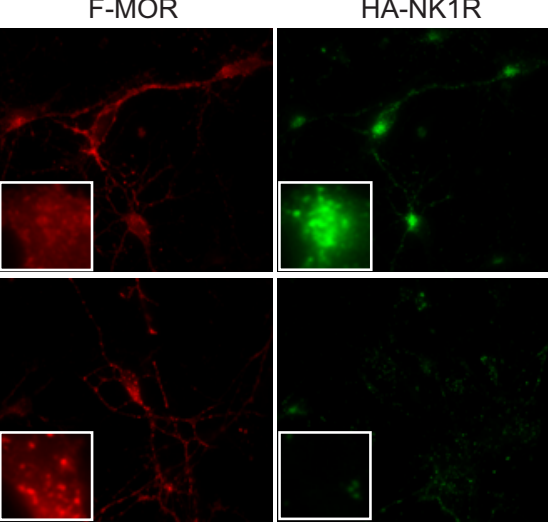

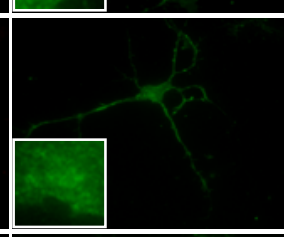

overlay

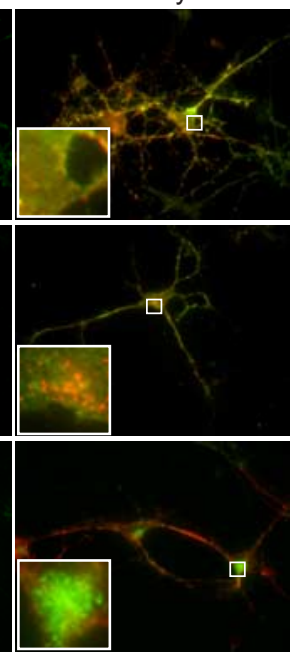

overlay

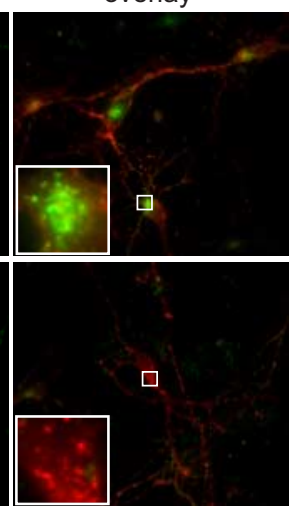

Figure 1. Morphine and substance $P$ drive redistribution of F-MOR and HA-NK1R selectively in striatal neurons. Dual-labeled HA-NK1R redistribution was indistinguishable from that exposed to SP alone (top). In neurons transfected with only F-MOR, addition of SP in the media had no effect on F-MOR redistribution in response to MS (bottom). Scale bar, $20 \mu \mathrm{m}$.

centrifugation at $1000 \times g$ for $5 \mathrm{~min}$ at room temperature. The concentration of cAMP present in clarified lysates was determined according to the nonacetylated version of the Correlate EIA Direct Cyclic AMP Enzyme Immunoassay Kit protocol (Assay Designs). Acute signaling response was calculated from ligand-induced inhibition of forskolinstimulated cAMP production relative to that measured in cells challenged with forskolin alone. Desensitization was estimated by the decrease in morphine-induced inhibition of cAMP accumulation measured in the rechallenge compared with that measured in cells not previously exposed to opiate. For examination of substance P effects on desensitization, only experiments in which morphine-driven MOR desensitization was reliably detected in the absence of substance $\mathrm{P}$ were included in the analysis. In each individual experiment, all manipulations and determinations were performed in triplicate and averaged. The number of independent experiments included in each comparison is indicated in the text. Statistical analyses of differences among experimental conditions were performed using unpaired $t$ test.

Receptor internalization in neurons from FLAG-MOR-Tg/+, MOR-/- mice

Four- to six-week-old mice were anesthetized with isoflurane, and the brain was removed and sliced horizontally (200 $\mu \mathrm{m}$ thickness) using a 

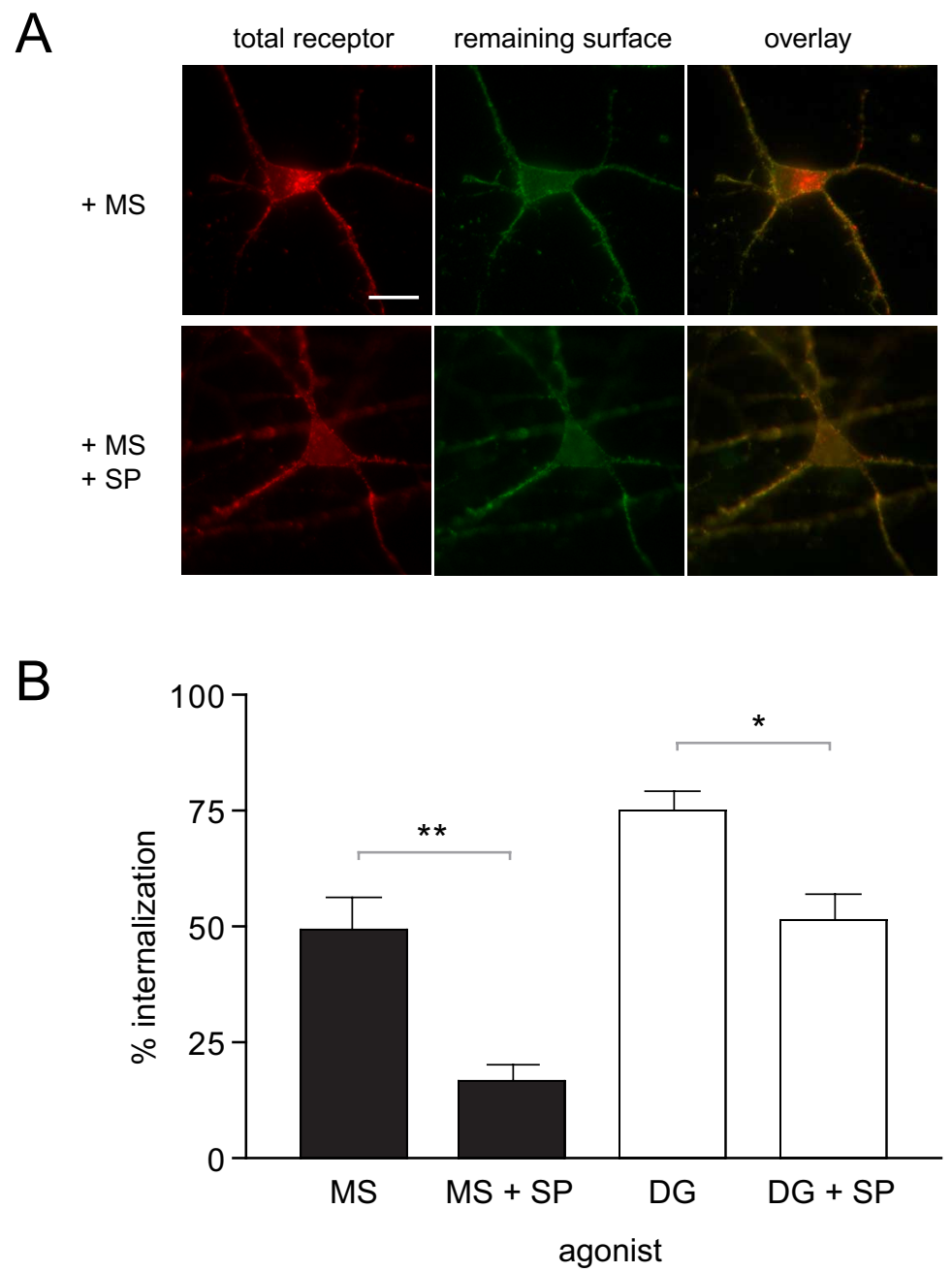

Figure 2. Regulated endocytosis of F-MOR is inhibited by SP-mediated activation of coexpressed HA-NK1R. Striatal neurons were transfected with F-MOR and HA-NK1R. A, Neurons were first incubated with M1-Alexa594 antibody (red) to label surface F-MORs (first column). After 30 min of agonist incubation, neurons were fixed under nonpermeabilizing conditions and incubated with Alexa488 (green) to label remaining F-MORs on the plasma membrane (middle column). Morphine treatment resulted in internalized punctate structures of labeled receptors (top left) that are not accessible to the cell surface (top middle). This is emphasized in the overlay image (top right). In neurons incubated with both MS and SP, total and remaining surface receptor labeling overlapped almost completely, indicating a lack of F-MOR internalization (bottom). $\boldsymbol{B}$, A ratio of green (surface receptors after agonist treatment) to red (total receptor) fluorescence intensity was used to determine percentage F-MOR internalization when incubated with either MS or DAMG0 alone, or in combination with SP (see Materials and Methods for detail). Bar graphs represent mean internalization determined from $\sim 50$ cell bodies selected at random in neuronal cultures and averaged over five independent cultures $\left({ }^{*} p<0.01,{ }^{* *} p<0.005\right)$. Scale bar, $10 \mu \mathrm{m}$.

vibratome (Leica) in ice-cold artificial CSF (ACSF) containing the following (in mM): $126 \mathrm{NaCl}, 2.5 \mathrm{KCl}, 1.2 \mathrm{MgCl}_{2}, 1.2 \mathrm{NaH}_{2} \mathrm{PO}_{4}, 2.4 \mathrm{CaCl}_{2}$, $21.4 \mathrm{NaHCO}_{3}$, and 11 glucose as previously described (Arttamangkul et al., 2008). Slices including the locus ceruleus were allowed to warm up to $34^{\circ} \mathrm{C}$ in oxygenated ACSF containing (+)-MK-801 (10 $\mu \mathrm{M}$, SigmaAldrich) for $15 \mathrm{~min}$ and then incubated in a solution containing Alexa 594-conjugated M1 antibody. The tissue was visualized with an upright microscope (Olympus) equipped with a custom-built two-photon apparatus, as described previously (Arttamangkul et al., 2008). Data were acquired and collected using Scan Image Software (Pologruto et al., 2003). A $z$-series was collected at $1 \mu \mathrm{m}$ intervals for $15 \mu \mathrm{m}$. Drugs were applied by perfusion. All experiments were done at $35^{\circ} \mathrm{C}$. Analyses were done off-line using Image ( $\mathrm{NIH}$ ) software as described in detail previously (Arttamangkul et al., 2008). For the control condition, integrated intensity data were obtained from labeled slices before drug application. This fluorescence intensity was defined as total surface-accessible receptor immunoreactivity $(C)$. Integrated fluorescence intensity measured after drug perfusion, followed by calcium-free ACSF containing $0.5 \mathrm{~mm}$
EGTA (10 min), was defined as internalized receptor immunoreactivity $(I)$. Percentage of internalization was calculated by $(I / C) \times 100$.

\section{Results}

Morphine and substance $P$ drive rapid redistribution of $\boldsymbol{\mu}$-opioid and neurokinin 1 receptors, respectively, in dissociated striatal neurons

To begin to investigate possible regulatory interactions between $\mu$-opioid receptors and neurokinin 1 receptors, we examined the subcellular distribution of receptors when coexpressed in dissociated striatal neurons. Cultured striatal neurons were cotransfected with FLAG-tagged $\mu$-opioid receptors (F-MOR) and HA-tagged neurokinin 1 receptors (HA-NK1R), and the localization of each receptor was examined by dual-label epifluorescence microscopy. In the absence of ligand (untreated condition), antibody-labeled F-MOR was observed in a distribution indicative of plasma membrane localization (Fig. $1 A$, top row, left panel). Similar surface localization was also observed with HANK1R (middle panel). The overlay image confirmed an overlap in distribution between F-MOR and HA-NK1R on the plasma membrane (right panel). Examination of the cell body at higher magnification emphasized the overlap in F-MOR and HA-NK1R localization (insets). Exposure of cells to $10 \mu \mathrm{M}$ morphine (MS) for $30 \mathrm{~min}$ produced a substantial redistribution of labeled F-MOR into a punctate intracellular pattern (Fig. $1 A$, middle row, left panel), consistent with morphine-induced endocytosis of MOR shown previously in these neurons (Haberstock-Debic et al., 2005). In contrast, morphine did not detectably affect the plasma membrane localization of labeled HA-NK1R (middle panel and overlay). Conversely, activating HA-NK1Rs with substance P (SP) resulted in selective internalization of HA-

NK1Rs, while F-MORs remained predominantly in the plasma membrane (Fig. $1 \mathrm{~A}$, bottom row).

\section{Activation of NK1R via substance $P$ inhibits regulated internalization of MOR}

We next examined the effects of activating both receptors by exposing neurons to morphine and substance $\mathrm{P}$ simultaneously. Labeled HA-NK1R redistributed rapidly into a punctate pattern in the combined presence of both agonists, indistinguishable from the redistribution observed in neurons exposed to substance $\mathrm{P}$ alone [Fig. 1, compare $B$ (top row) with $A$ (bottom row)]. Surprisingly, F-MORs coexpressed on these same cells remained localized predominantly in the plasma membrane, in contrast to the pronounced redistribution observed in the presence of morphine alone [Fig. 1, compare $B$ (top row) with $A$ 

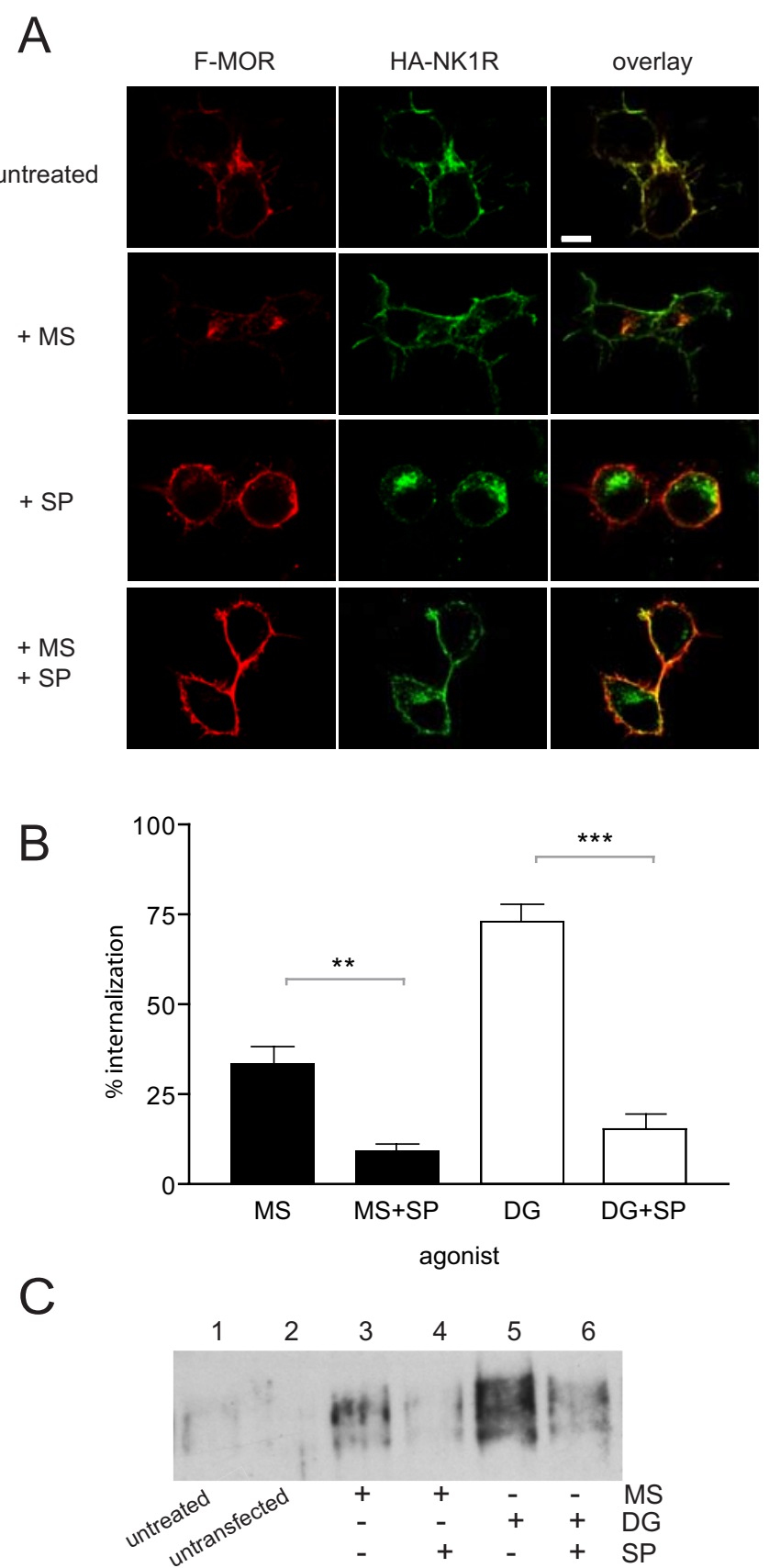

Figure 3. Heterologous regulation of F-MOR endocytosis in mouse neuroblastoma (N2A) cells. $\boldsymbol{A}$, Dual-labeled confocal fluorescence micrographs show F-MOR (red) and HA-NK1R (green) transiently expressed in N2A cells. In untreated cells, both F-MOR and HA-NK1R showed a plasma membrane distribution, with minimal labeled receptors present internally in the cell (top). Incubation with either $10 \mu \mathrm{M}$ MS or $10 \mu \mathrm{M}$ SP for 30 min resulted in a selective increase in either labeled F-MORs (second row, first panel) or HA-NK1Rs (third row, middle panel), respectively, present internally in the cell. Simultaneous incubation with MS and SP produced visibly less F-MOR internalization than incubation with MS alone (bottom row, first panel). Scale bar, $10 \mu \mathrm{m}$. B, Quantification of ratiometric staining in N2A cells shows inhibition of F-MOR internalization in response to both $M S$ and $D G$ when $S$ was also present. Bar graphs represent mean internalization determined from $\sim 50$ cell bodies selected at random in N2A cultures and averaged over five independent transfections $\left({ }^{* *} p<0.005,{ }^{* * *} p<0.0005\right)$. C, Isolated biotinylated F-MORs were detected by immunoblotting with anti-FLAG antibody in N2A cells coexpressing both F-MOR and HA-NK1R. Incubation with both SP and MS (lane 4) or DG (lane 6), compared with either MOR agonist alone (lanes 3 and 5), for 30 min resulted in a decrease in the internalized pool of F-MORs ( $n=3$ independent experiments). (middle row)]. This selective redistribution of HA-NK1R was more clearly evident when viewed at higher magnification (inset). To investigate whether this nonreciprocal inhibition of F-MOR redistribution was dependent on the presence of HANK1Rs, we identified cells on the same coverslip expressing only F-MOR and not HA-NK1Rs. In these neurons, incubation with both morphine and substance $\mathrm{P}$ produced robust redistribution of F-MOR into a punctate pattern, similar to what was observed with morphine alone (Fig. $1 B$, bottom row). Together, these results show that morphine-induced redistribution of F-MOR in neurons is specifically inhibited by simultaneous activation of coexpressed HA-NK1Rs by substance P.

To determine whether the agonist-mediated receptor redistribution observed by immunofluorescence is the result of receptor endocytosis, we used a previously described dual-labeling method to distinguish between surface-localized and internalized MORs (Haberstock-Debic et al., 2005). F-MORs present in the plasma membrane were initially surface-labeled using Alexa594conjugated anti-FLAG monoclonal antibody. After $30 \mathrm{~min}$ of ligand incubation, neurons were fixed and receptors remaining in the plasma membrane were selectively labeled with Alexa488conjugated secondary antibody (Fig. $2 \mathrm{~A}$, middle column). Internalized receptors appeared red, whereas plasma membranelocalized receptors labeled with both fluorochromes appeared yellow in the overlay image (Fig. 2A). Representative images of striatal neurons revealed that a significant fraction of F-MOR present initially in the plasma membrane internalized following exposure of neurons to morphine for $30 \mathrm{~min}$ (Fig. 2A, top row). In contrast, incubation of neurons with both morphine and substance $\mathrm{P}$ resulted in little internalization of F-MOR, demonstrated by an overlap in staining of total receptor and remaining surface receptor (Fig. 2A, bottom row). Ratiometric quantification in multiple neurons (as described in Materials and Methods) confirmed the significant inhibitory effect of HA-NK1R activation on regulated endocytosis of F-MOR (Fig. $2 \mathrm{~B}$, black bars).

The enkephalin analog D-Ala ${ }^{2}-\mathrm{N}-\mathrm{Me}-\mathrm{Phe}^{4}-\mathrm{Glycol}^{5}$ enkephalin (DAMGO) is known to drive MOR endocytosis more readily and to a greater degree than morphine in many cell types (Keith et al., 1998; Whistler et al., 1999; Bushell et al., 2002; Trafton and Basbaum, 2004). Thus we tested whether activation of NK1Rs receptors can also inhibit endocytosis of MOR induced by DAMGO. Incubation of striatal neurons with $10 \mu \mathrm{M}$ DAMGO for $30 \mathrm{~min}$ produced substantial internalization of F-MOR, which was somewhat larger in absolute magnitude than that induced by morphine (Fig. $2 \mathrm{~B}$, white bars). Coapplication of substance $\mathrm{P}$ resulted in a less pronounced, but still significant, inhibition of F-MOR endocytosis. Thus, NK1R-mediated inhibition of MOR trafficking is not restricted to opiate drugs such as morphine, and can also affect regulated endocytosis induced by opioid peptide.

\section{Regulated MOR endocytosis is inhibited by NK1R activation in $\mathrm{N} 2 \mathrm{~A}$ cells}

We next asked whether the pronounced inhibitory effect of NK1R activation on MOR trafficking could be observed in a cultured cell model that is advantageous for mechanistic and biochemical studies. Typically, morphine drives endocytosis of MORs poorly in transformed cell lines (Keith et al., 1996; Alvarez et al., 2002). Nevertheless, by surveying a number of neurosecretory cell types, we found rapid morphine-mediated endocytosis of MORs in mouse-derived Neuro2A (N2A) cells. We first assessed the subcellular translocation of F-MOR and HA-NK1Rs with antibody labeling of cells transiently coexpressing these two 


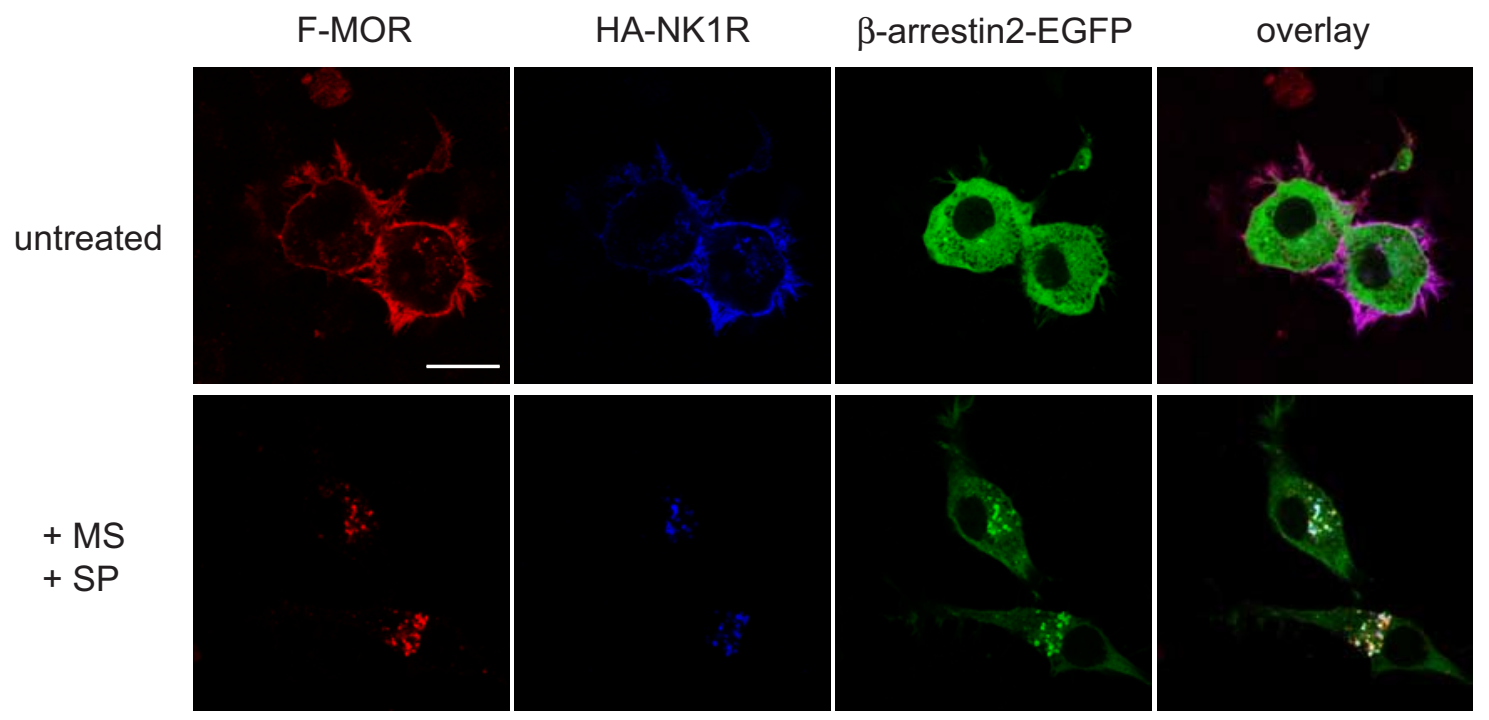

Figure 4. Overexpression of $\beta$-arrestin2-EGFP in N2A cells coexpressing F-MOR and HA-NK1R prevents inhibition of F-MOR endocytosis. Confocal fluorescence micrographs of N2A cells coexpressing F-MOR (red), HA-NK1R (blue), and $\beta$-arrestin2-EGFP (green). Overexpression of $\beta$-arrestin2 resulted in internalization of F-MOR (bottom row, first panel) in response to 30 min of 10 $\mu \mathrm{m}$ MS even in the presence of $10 \mu \mathrm{M}$ SP. Internalization of HA-NK1R was not detectably affected by $\beta$-arrestin2 overexpression (bottom row, second panel). Scale bar, $20 \mu \mathrm{m}$.

receptors under various agonist conditions. Confocal microscopy demonstrated a predominantly plasma membrane distribution of both receptor types in the absence of ligand (Fig. $3 A$, top row). Exposure to $10 \mu \mathrm{M}$ morphine for $30 \mathrm{~min}$ selectively promoted redistribution of F-MORs to intracellular vesicles, whereas HA-NK1Rs remained predominantly on the cell surface (Fig. 3A, second row). Conversely, incubation with substance $\mathrm{P}$ resulted in selective internalization of HA-NK1Rs but not F-MORs (Fig. 3A, third row). Further replicating the results obtained in striatal neurons, simultaneous incubation of N2A cells with both morphine and substance $\mathrm{P}$ resulted in selective internalization of HA-NK1Rs and little visible redistribution of F-MOR from the plasma membrane (Fig. $3 A$, bottom row). Quantification by ratiometric imaging confirmed the inhibitory effect of HA-NK1R activation on morphine-induced endocytosis of F-MORs (Fig. 3B, black bars). DAMGO-induced internalization of F-MOR was also significantly inhibited by HA-NK1R activation in N2A cells, and this was even more pronounced than observed in striatal neurons (Fig. $3 B$, white bars).

To further confirm the HA-NK1R-dependent inhibition of F-MOR endocytosis, we used a biochemical assay to specifically measure the fate of surface-biotinylated receptors in a population of cells coexpressing both F-MOR and HA-NK1R. Cells were surface biotinylated and then subjected to agonist incubation for $30 \mathrm{~min}$. Biotin attached to receptors remaining in the plasma membrane was selectively cleaved using a membraneimpermeant reducing agent, and the internalized (still biotinylated) pool of F-MORs was selectively detected following isolation on streptavidin beads. Very little biotinylated signal was detected in cells incubated in the absence of opioid agonist, confirming the efficiency of the cleavage reaction and, as expected, both morphine and DAMGO produced significant internalization of F-MORs (a representative immunoblot is shown in Fig. 3C; compare lane 1 with lanes 3 and 5). F-MOR internalization induced by both opioid agonists was dramatically reduced, essentially to the level of untreated control cells, when cells were incubated in the presence of substance $\mathrm{P}$ together with either morphine or DAMGO (Fig. 3C, compare lanes 3 and 5 with lanes 4 and 6).
NK1R-dependent inhibition of MOR endocytosis is mediated by receptor-specific trafficking of arrestin to endosomes

What is the mechanism underlying the HA-NK1R-dependent inhibition of MOR endocytosis? Given that NK1R is a $\mathrm{G}_{\mathrm{q}}-$ coupled receptor, one possibility is endocytic inhibition could occur as a consequence of $\mathrm{G}_{\mathrm{q}}$-mediated signaling via phospholipase C (PLC). This hypothesis is potentially consistent with a previous report that protein kinase $C$ (an effector of the $G_{q}-P L C$ pathway) can inhibit MOR internalization (Ueda et al., 2001), but is contradicted by the recent finding that activation of a distinct $\mathrm{G}_{\mathrm{q}}$-coupled receptor (the $5-\mathrm{HT}_{2 \mathrm{~A}}$ serotonin receptor) enhances rather than inhibits MOR internalization (LopezGimenez et al., 2008). Further arguing against this hypothesis, we found that blocking PLC activity in N2A cells using the specific inhibitor U73122 did not prevent NK1R-dependent inhibition of MOR endocytosis (supplemental Fig. 1, available at www. jneurosci.org as supplemental material). Another hypothesis is that the observed endocytic inhibition is caused by depletion of functional arrestin activity from the cytoplasm by sequestration on the endosome membrane. Whereas many GPCRs (including MOR) rapidly dissociate from arrestins upon endocytosis, a subset of GPCRs (including the NK1R) are capable of driving pronounced sequestration of arrestins on endosomes (Oakley et al., 2001). Further, endosomal sequestration by such GPCRs was shown previously to mediate heterologous inhibition of endocytosis of nonsequestering GPCRs in non-CNS cells (Klein et al., 2001; Schmidlin et al., 2002). To examine whether depletion of arrestin might mediate HA-NK1R-dependent inhibition of MOR endocytosis in neuronal cells, we first asked whether increasing cytoplasmic arrestin by overexpression is sufficient to rescue morphine-induced endocytosis of MOR. To do so we focused on arrestin 3 ( $\beta$-arrestin2), which is expressed natively in the striatum and extended amygdala (Gurevich et al., 2002). EGFPtagged $\beta$-arrestin 2 was transfected into $\mathrm{N} 2 \mathrm{~A}$ cells coexpressing F-MOR and HA-NK1Rs, and triple color confocal microscopy was used to detect and localize each of the proteins specifically. In contrast to cells expressing arrestins at endogenous levels, coactivation of HA-NK1Rs in cells overexpressing $\beta$-arrestin 2 failed 

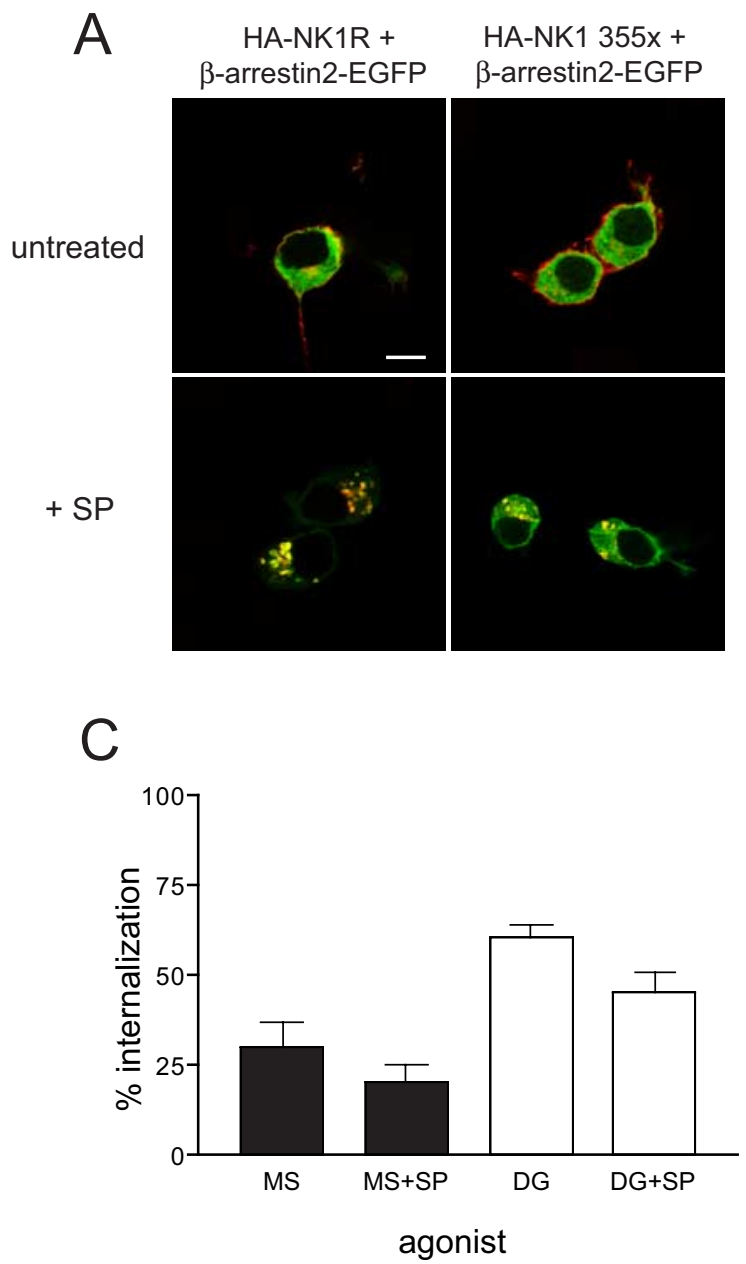

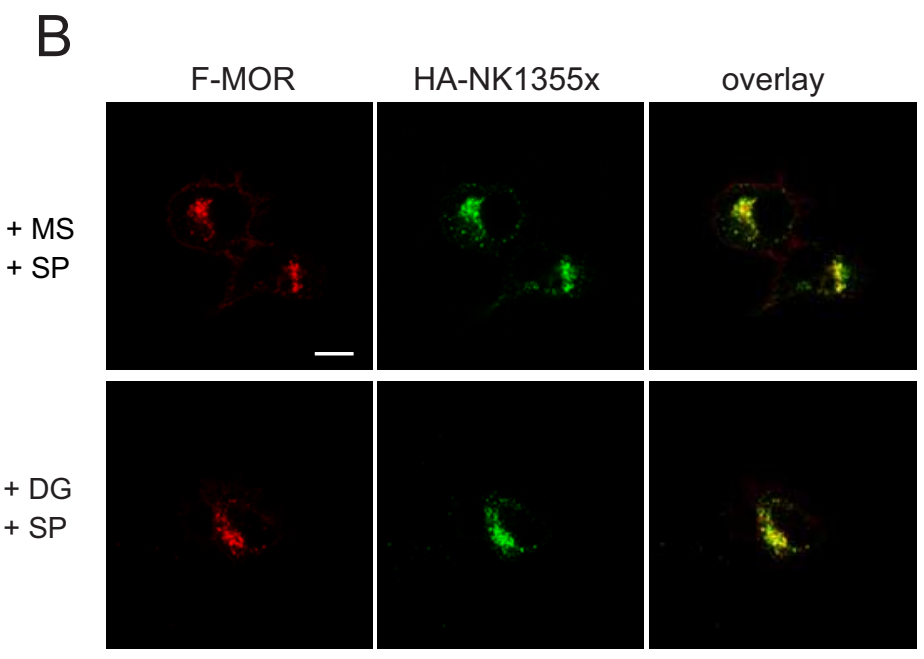

D

Figure 5. Mutational disruption of NK1R-mediated sequestration of $\beta$-arrestin prevents inhibition of F-MOR endocytosis in N2A cells. $\boldsymbol{A}$, Confocal micrographs of N2A cells coexpressing either full-length HA-NK1R (left panels, red) or truncated HA-NK1R (right panels, red) with $\beta$-arrestin2-EGFP (green). Incubation with $10 \mu \mathrm{m}$ SP in cells expressing the truncated HA-NK1R (355x) resulted in less colocalization with receptors in endosomal clusters and higher cytoplasmic $\beta$-arrestin2-EGFP distribution (left column) than $\beta$-arrestin2-EGFP distribution in the wild-type HA-NK1R under the same conditions (right column). Scale bar, $10 \mu \mathrm{m} . \boldsymbol{B}$, In N2A cells coexpressing F-MOR (red) and HA-NK1 355x receptors (green), both morphine and DAMG0 were able to drive internalization of F-MORs even in the presence of substance P. Scale bar, $10 \mu \mathrm{m}$. C, Quantification using ratiometric staining of F-MORs in N2A cells coexpressing HA-NK1 355x revealed that coincubation with SP produced levels of F-MOR internalization similar to treatment with either MS or DG alone. Bar graphs represent mean internalization determined from $\sim 50$ cell bodies selected at random in the N2A cultures and averaged over four independent transfections. $D$, Biochemical assay of F-MOR internalization by surface biotinylation confirmed that F-MOR internalization induced by either MS or DG (lanes 3 and 5) was not significantly inhibited by coapplication of SP (lanes 4 and $6 ; n=3$ independent experiments).

to inhibit morphine-induced endocytosis of F-MOR (Fig. 4). This was indicated by the ability of both F-MOR and HA-NK1Rs to endocytose rapidly to an overlapping population of endocytic vesicles in cells exposed to both morphine and substance $\mathrm{P}$, and these endocytic vesicles also visibly sequestered EGFP-tagged $\beta$-arrestin2 from the cytoplasm.

To determine whether arrestin sequestration occurs in N2A cells, we coexpressed HA-NK1R and EGFP-tagged $\beta$-arrestin2 and examined arrestin redistribution after substance $P$ treatment. Immunofluorescence analysis confirmed that activation of HANK1R for $30 \mathrm{~min}$ was sufficient to promote rapid and pronounced redistribution of EGFP-tagged $\beta$-arrestin 2 to receptorcontaining endosomes (Fig. 5A, left column). This effect was specific to HA-NK1Rs because activation of F-MORs with either morphine or DAMGO alone did not produce detectable sequestration of arrestin on endosomes (data not shown). By truncating a distal portion of the HA-NK1R tail (HA-NK1 355x), we were able to disrupt substance $\mathrm{P}$-induced arrestin sequestration on endosomes (Fig. 5A, right column). This portion of the NK1R tail was previously shown to be required for endosomal sequestration of arrestins in non-neural cells (Oakley et al., 2001). Importantly, substance P-induced receptor endocytosis was not blocked by this mutation (Fig. $5 A$, bottom right).

We next asked whether disrupting arrestin sequestration prevents endocytic inhibition of MORs in cells expressing arrestins at endogenous levels. N2A cells expressing F-MOR and HA-NK1 $355 \mathrm{x}$ were exposed to their respective agonists individually or in combination. As expected, incubation with morphine or substance $\mathrm{P}$ alone selectively promoted endocytosis of F-MORs or HA-NK1Rs, respectively (data not shown). However, rapid endocytosis of both F-MORs and HA-NK1 355x receptors was also observed in cells exposed to both morphine and substance $\mathrm{P}$, in contrast to the endocytic inhibition of MOR produced by coactivation of the wild-type HA-NK1R (Fig. 5B, top panels). Similarly, incubation with DAMGO also resulted in MOR endocytosis, even in the presence of substance $\mathrm{P}$ (Fig. $5 B$, bottom panels).

Ratiometric quantification of F-MOR internalization in N2A cells coexpressing HA-NK1 355x confirmed that the degree of internalization observed in cells exposed to both morphine and substance $\mathrm{P}$ was not significantly different from that observed 


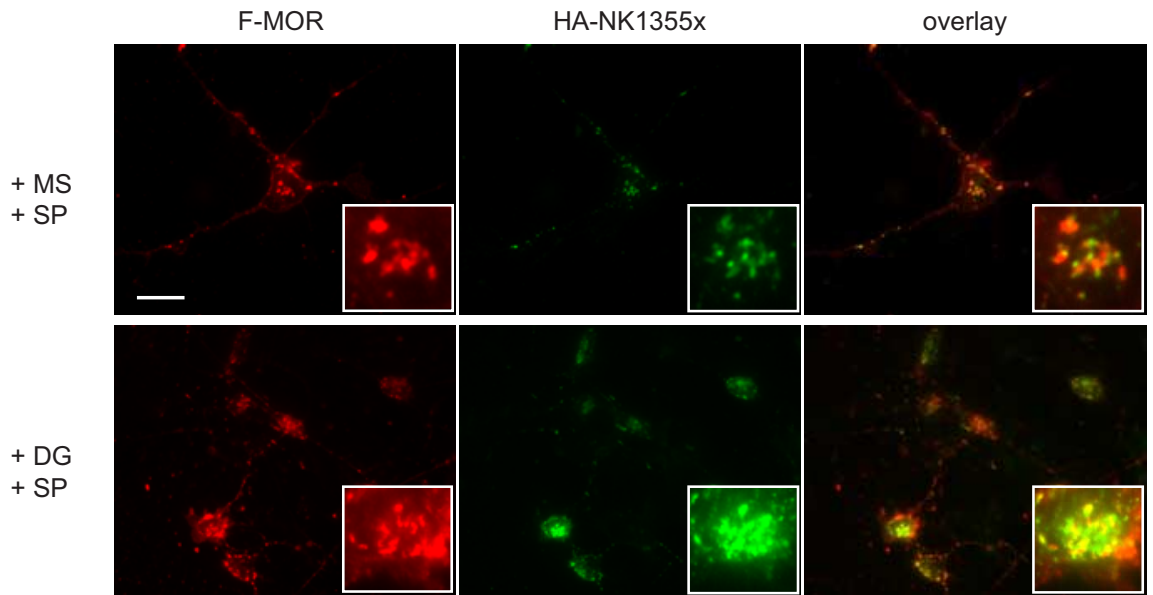

Figure 6. Mutational disruption of NK1R-mediated sequestration of $\beta$-arrestin prevents inhibition of F-MOR endocytosis in striatal neurons. Dual-labeled epifluorescence micrographs show F-MOR (red) and HA-NK1R (green) distribution in striatal neurons. Insets within images show magnification of representative receptor distribution. Incubation with $10 \mu \mathrm{M}$ MS for 30 min resulted in a redistribution of F-MORs in striatal neurons even in the presence of $10 \mu \mathrm{M} S P$ when the truncated version of the NK1R was coexpressed with F-MOR (top row). A similar redistribution of F-MOR was observed when neurons were incubated with both $10 \mu \mathrm{m}$ DG and SP. Scale bar, $20 \mu \mathrm{m}$.

when exposed to morphine alone (Fig. 5C, black bars). Similarly, the endocytic inhibitory effect on DAMGO-induced internalization was also greatly reduced (Fig. 5C, white bars). Biochemical analysis using surface biotinylation of receptors further confirmed this loss of endocytic inhibition. Addition of substance P to the culture medium did not detectably reduce the internalized pool of F-MORs produced by either morphine or DAMGO (Fig. $5 D$, compare lanes 3 and 5 with lanes 4 and 6). Together, these results strongly suggest that endosomal sequestration of arrestin by activated HA-NK1Rs is both necessary and sufficient to produce the observed inhibition of F-MOR endocytosis in N2A cells.

To determine whether a similar mechanism mediates the NK1R-dependent endocytic inhibitory effect in striatal neurons, we performed the equivalent experiment in primary neuronal cultures coexpressing F-MOR and HA-NK1 355x. In contrast to the significant inhibition of morphine-induced endocytosis of F-MOR observed in cells produced by activating wild-type HANK1Rs, substance P-mediated activation of HA-NK1 355x did not prevent morphine induced endocytosis of F-MOR (Fig. 6 top panels; compare with Fig. $1 \mathrm{~B}$ ). DAMGO-induced endocytosis of F-MOR was also not detectably impaired by activation of coexpressed HA-NK1 355x receptors (Fig. 6, bottom panels).

\section{NK1R-dependent regulation selectively inhibits MOR desensitization, without affecting acute signaling, in opioid- naive neurons}

To begin to assess the functional significance of this arrestindependent MOR-NK1R regulatory effect, we examined MOR signaling via heterotrimeric G-proteins. Because MORs couple primarily to $G_{i}$, we used forskolin to stimulate adenylyl cyclase activity and examined MOR signaling via inhibition of forskolininduced cAMP production in cultured striatal neurons coexpressing F-MORs and HA-NK1Rs. As expected, exposure of neurons to morphine for $3 \mathrm{~min}$ significantly inhibited cAMP production (Fig. 7A). This acute signaling response was not detectably affected by coactivation of HA-NK1Rs with substance P. Furthermore, consistent with HA-NK1R coupling primarily to $\mathrm{G}_{\mathrm{q}}$, substance P-mediated activation of HA-NK1Rs in the ab- sence of opiate did not change cAMP levels detectably from the control (i.e., forskolin only) condition.

To examine whether NK1R-mediated inhibition of MOR endocytosis is associated with an effect on MOR desensitization, we assayed the ability of morphine to inhibit cAMP accumulation in neurons preexposed to agonist. Preincubation of neurons with morphine for $30 \mathrm{~min}$ attenuated the ability of a second challenge of morphine to inhibit forskolin-stimulated cAMP accumulation in neurons, compared with the morphine-induced inhibition observed in opiate-naive neurons (Fig. $7 B$, compare bars 2 and 3 from the left). Interestingly, this morphine-induced attenuation of subsequent opiate response was significantly reduced by inclusion of substance $\mathrm{P}$ in the preincubation (Fig. $7 B$, compare bars 3 and 4 from the left). We verified in control experiments that forskolin-stimulated cAMP accumulation measured in the absence of opioid did not differ significantly between the pretreatment conditions when compared with drug-naive neurons (supplemental Fig. 2, available at www.jneurosci.org as supplemental material). Together, these results indicate that NK1R activation does not detectably affect acute opiate signaling, but significantly reduces functional desensitization of MOR signaling produced by opiate preexposure.

\section{MOR endocytosis is inhibited by NK1R activation in a} neuronal population expressing endogenous receptors To determine whether a similar inhibition of MOR endocytosis can occur with receptors expressed at endogenous levels, we explored this phenomenon in several populations of neurons where both MOR and NK1Rs are reportedly coexpressed. In our cultures, immunocytochemical staining of dissociated striatal cultures revealed that MOR and NK1Rs were expressed largely in distinct neurons, making this preparation unfavorable for examining heterologous regulation of endogenous receptor trafficking (data not shown).

Another brain region that is known to coexpress these receptors and modulate behavioral reward to opioids is the amygdala (Nakaya et al., 1994; Gadd et al., 2003; Poulin et al., 2006). We cultured primary rat amygdala neurons and found that a subset of these neurons were positive for both endogenous MOR and NK1R immunoreactivity, while others expressed only one but not the other receptor type. In neurons expressing MORs but not NK1Rs, incubation of cultures with both $10 \mu \mathrm{M}$ DAMGO and substance $\mathrm{P}$ for $30 \mathrm{~min}$ resulted in a pronounced redistribution of MOR immunoreactivity, indicative of rapid internalization of MORs (Fig. 8A, top left). In contrast, redistribution of MORs was substantially reduced in neurons coexpressing both MORs and NK1Rs under the same agonist conditions, while NK1R endocytosis in response to substance $\mathrm{P}$ was unaffected (Fig. $8 \mathrm{~A}$, bottom row). We verified in control experiments that DAMGO alone stimulated a pronounced redistribution of MOR in both NK1Rpositive and -negative neurons (data not shown). These results suggest that inhibition of MOR internalization by NK1R activation also occurs in neurons that endogenously express these receptors. 
A

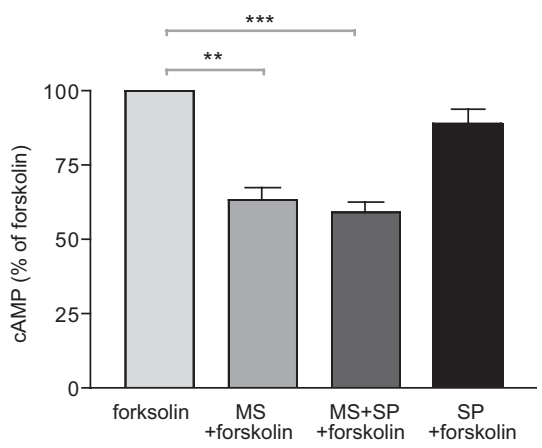

B

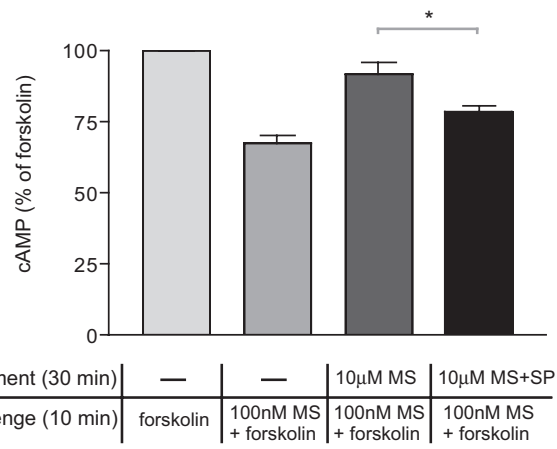

Figure 7. NK1R-mediated inhibition of MOR endocytosis is associated with reduced functional desensitization of opioid-dependent regulation of adenylyl cyclase. Striatal neurons coexpressing F-MOR and HA-NK1R were cultured and assayed for cAMP levels (see Materials and Methods). $\boldsymbol{A}$, The amount of (AMP accumulated in response to adenylyl cyclase stimulation with $3 \mu \mathrm{m}$ forskolin was defined as $100 \%$ cAMP production (left bar). Bars represent mean forskolinstimulated CAMP accumulation observed in the presence of a saturating concentration (10 $\mu \mathrm{M})$ of morphine (MS), substance P (SP), or both $\left(n=4,{ }^{* *} p<0.005,{ }^{* * *} p<0.0005\right)$. $\boldsymbol{B}$, Neurons were preincubated for $30 \mathrm{~min}$ in the absence or presence of $10 \mu \mathrm{M}$ MS alone, or $10 \mu \mathrm{m}$ MS together with $10 \mu \mathrm{M} S \mathrm{~S}$. After agonist washout, neurons were rechallenged for $10 \mathrm{~min}$ with a subsaturating concentration (100 nm) of MS together with $3 \mu \mathrm{m}$ forskolin. Bars represent mean CAMP accumulation measured in the rechallenge period compared with that induced by forskolin alone in previously untreated neurons $\left(n=4,{ }^{*} p<0.05\right)$.

\section{MOR endocytosis is inhibited by NK1R activation in locus ceruleus neurons}

To test whether cross-inhibition occurs in another relevant population of CNS neurons, and to obtain quantitative data, we examined the effect of substance $\mathrm{P}$ on MOR internalization using locus ceruleus neurons from F-MOR Tg+/-, MOR $-/-$ mice (Arttamangkul et al., 2008). This brain region consists primarily of noradrenergic neurons, which possess a high density of both endogenous MORs and NK1Rs (Cheeseman et al., 1983; Tempel and Zukin, 1987; Nakaya et al., 1994). In slices imaged in the absence of agonist, immunoreactive MOR was localized primarily in the plasma membrane, as indicated by the peripheral staining pattern in two-photon optical sections (Fig. $8 B$, top left panel). Because morphine does not cause significant internalization in LC neurons, [Met] ${ }^{5}$ enkephalin (ME) was used in these experiments (Arttamangkul et al., 2008). Bath application of 10 $\mu \mathrm{M}$ ME for $15 \mathrm{~min}$ induced a redistribution of F-MOR receptors to a punctate pattern consistent with regulated endocytosis of MOR (Fig. $8 B$, top middle panel). This was confirmed by subsequent application of calcium-free EGTA solution, which dissociates antibody from surface-accessible receptors, leaving the inter- nalized receptor pool specifically labeled (Fig. $8 B$, top right panel). Application of $10 \mu \mathrm{M}$ substance $\mathrm{P}$ to slices did not detectably change the plasma membrane localization pattern of labeled MOR (Fig. $8 B$, bottom left panel), indicating that activating the NK1Rs alone did not promote significant internalization of MOR. Subsequent application of ME, in the continued presence of substance P, produced some redistribution of MOR but the magnitude of this effect was visibly reduced compared with that observed in slices exposed to ME alone (Fig. $8 \mathrm{~B}$, middle panels). Consistent with this, the internalized fraction of labeled MOR, which is resistant to the EGTA strip condition, was also visibly reduced in slices exposed to $\mathrm{ME}$ in the presence of substance $\mathrm{P}$ (Fig. 8 B, right panels). Quantification of these results over multiple experiments confirmed that substance P significantly inhibited ME-induced internalization of MOR in locus ceruleus neurons (Fig. 8C).

\section{Discussion}

The present results demonstrate that NK1R activation mediates a pronounced and cell-autonomous inhibition of MOR endocytosis induced by diverse opioid agonists. Whereas either morphine or DAMGO promote rapid endocytosis of MOR in striatal neurons, simultaneous activation of NK1Rs with substance $P$ strongly inhibited this fundamental regulatory process. We identified a transformed neurosecretory cell line in which pronounced morphine-induced endocytosis of MOR also occurs, and observed a similar endocytic inhibition mediated by NK1R activation in these cells. Our results indicate that, in both cell types, inhibition of MOR endocytosis is mediated by NK1Rdependent sequestration of arrestins on endosomes. This cellautonomous regulatory mechanism was also found to produce a functionally significant attenuation of morphine-induced desensitization of MOR signaling via adenylyl cyclase. Furthermore, heterologous regulation of MOR trafficking was established in two additional populations of CNS neurons that mediate behavioral effects of opiate drugs and was observed in neurons expressing receptors at endogenous levels. Together, these observations strongly suggest that NK1Rs can significantly modulate both trafficking and downstream signaling of MORs in multiple populations of physiologically relevant CNS neurons.

Our findings thus identify a novel mode of functional interaction between MORs and NK1Rs. A previous study of these two GPCRs expressed in a non-neural cell model (HEK293 cells) reported that ligand-induced activation of either MOR or NK1R promoted coendocytosis of both GPCRs by formation of MOR/ NK1R heterodimers (Pfeiffer et al., 2003). Such heterodimerdriven endocytic "dragging" was not clearly evident in the present study, as opioid and neurokinin agonists selectively promoted endocytosis of MORs and NK1Rs, respectively. Furthermore, several observations argue that the regulatory interaction revealed in the present study cannot be explained by heterodimer formation. First, activation of NK1Rs inhibited, rather than promoted, MOR endocytosis. Second, we did not observe rapid endocytosis of either MOR or NK1R in the absence of the appropriate receptor agonist. Third, the observed cross-regulatory effect was nonreciprocal, as NK1R activation inhibited MOR endocytosis but not vice versa. The present results do not exclude heterodimer-based regulation of opioid receptors by neurokinins, and we are aware that the degree to which various GPCRs form heteromeric complexes varies among cell types (Bouvier, 2001). Our findings argue strongly, however, that the distinct mechanism established in the present study plays a dominant role in mediating functional interaction between MOR and NK1Rs in CNS neurons. 


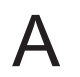

MOR (no NK1R)

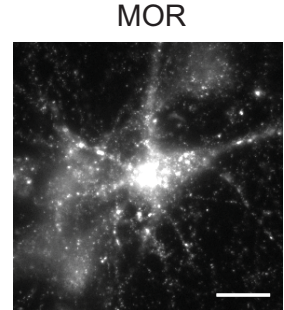

NK1R
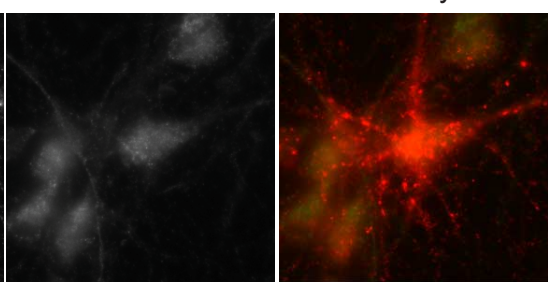

MOR+NK1R
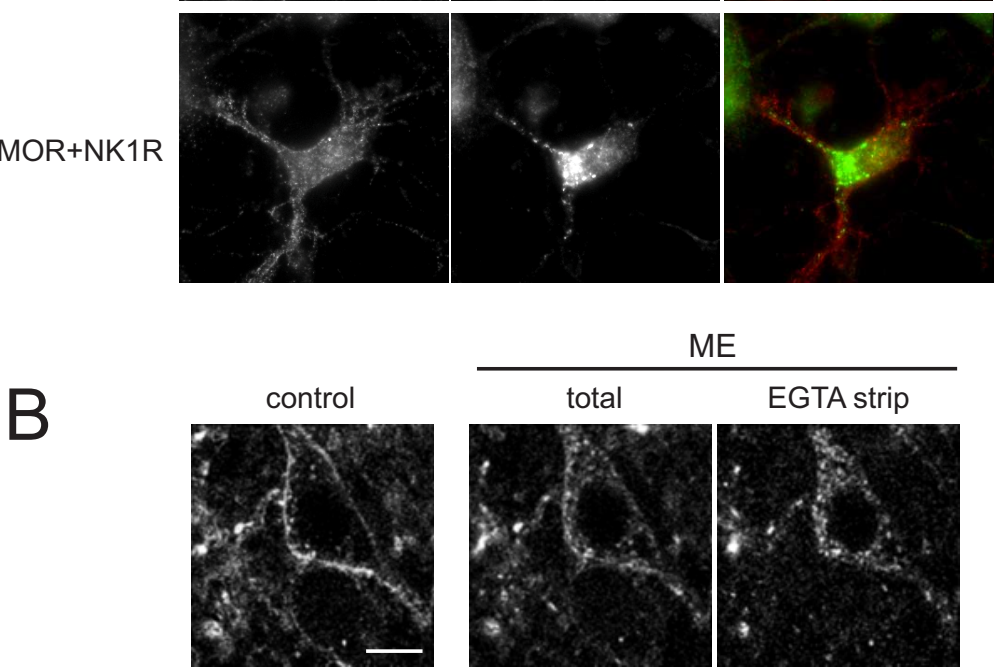

ME

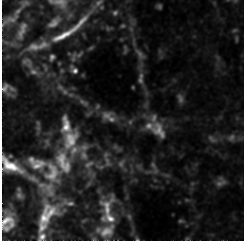

SP

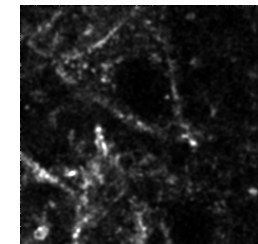

total
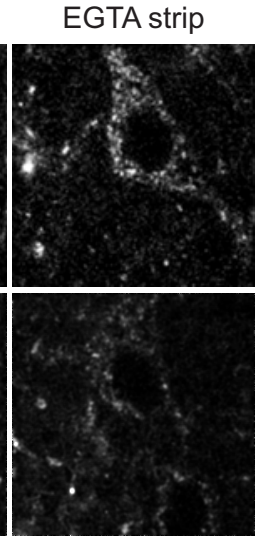

EGTA strip

$\mathrm{ME}+\mathrm{SP}$
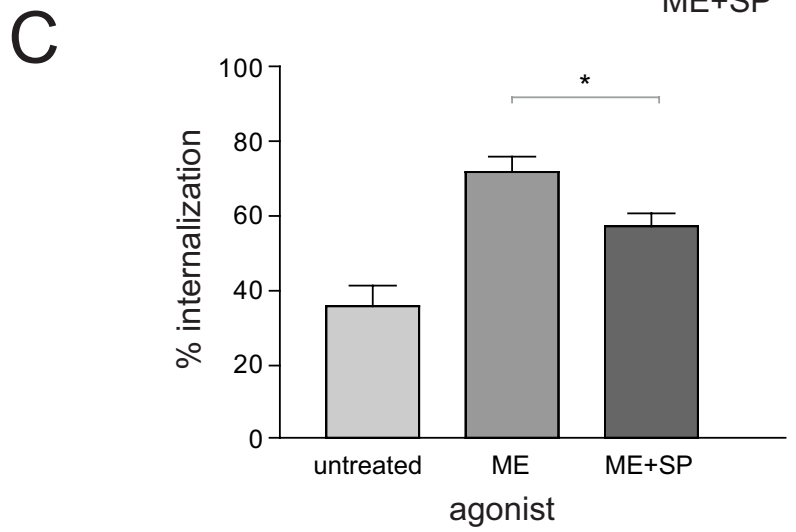

Figure 8. Heterologous inhibition of MOR endocytosis mediated by endogenously expressed NK1Rs. A, Dual localization of endogenous MORs and NK1Rs was visualized in dissociated amygdala cultures after coincubation with $10 \mu \mathrm{M}$ DAMGO and $10 \mu \mathrm{M}$ SP for $30 \mathrm{~min}$. Pronounced internalization of endogenous MOR was observed in cells not expressing detectable NK1R immunoreactivity (top), while internalization of MOR was dramatically inhibited in neurons (visualized on the same coverslip) expressing both MOR and NK1R (bottom). Epifluorescence images shown are representative of three independent experiments and were processed in parallel. Scale bar, $10 \mu \mathrm{m}$. B. Two-photon fluorescence imaging of F-MOR trafficking in live locus ceruleus neurons prepared from F-MOR-Tg/+, MOR-/- mice. F-MORs present in the plasma membrane were labeled by incubating acutely prepared brain slices with M1-Alexa594 for $45 \mathrm{~min}$ (top left). The same neuron was then perfused with $10 \mu \mathrm{m}$ [Met] ${ }^{5}$ enkephalin (ME) for $15 \mathrm{~min}$ (top middle). Remaining surface-accessible receptors were then stripped by adding calcium-free buffer containing EGTA (top right). The same series of manipulations performed in the presence of $10 \mu \mathrm{m}$ SP perfusion (bottom). Examples of midplane optical sections are shown. C, Summary of the internalization results obtained by measurement of EGTA-resistant Alexa594 measured in neurons across multiple experiments. ME exposure increased F-MOR uptake from residual levels $36 \pm 5 \%$ $(n=3)$ to $71.5 \pm 4.4 \%(n=15)$. Application of ME in the presence of SP significantly reduced FLAG-MOR uptake $(57.1 \pm 3.7 \%$, $n=15,{ }^{*} p=0.01$ ). Each experiment represents imaging of a different brain slice, compiled from dissection of 11 animals. Scale bar, $10 \mu \mathrm{m}$.

Cell autonomous, nonreciprocal endocytic inhibition has been observed previously among various GPCRs in nonneural cells as well as myenteric neurons (Klein et al., 2001; Schmidlin et al., 2002), and is consistent with the existence of significant differences among individual GPCRs in their ability to mediate arrestin trafficking from the cytoplasm to the endosome membrane (Oakley et al., 1999). NK1Rs, in particular, are able to mediate arrestin sequestration on endosomes in HEK293 cells (Oakley et al., 2001; Schmidlin et al., 2002). To our knowledge the present results are the first to demonstrate that arrestin sequestration can mediate heterologous regulation of GPCR trafficking in CNS neurons. Second, we show that this links NK1R activation to regulation of MORs in multiple populations of CNS neurons relevant to the behavioral effects of opiate drugs, and that this regulation can be observed among endogenously expressed receptors. Thus, we believe that arrestin trafficking to endosome membranes likely represents a fundamental mechanism for integrating receptor-mediated signaling effects across distinct GPCRs in diverse neural cell types. Furthermore, this function of arrestin trafficking in signal integration is clearly distinct from the previously proposed role of endosomeassociated arrestins in scaffolding signaling complexes on the endosome membrane in response to activation of particular GPCRs (Lefkowitz et al., 2006). Although the actual stoichiometry of nonvisual arrestins (or $\beta$-arrestins) relative to GPCRs is not clearly established in native cell types, our finding that endogenously expressed receptors mediate significant heterologous inhibition in both amygdala and locus ceruleus neurons suggests that the effective functional activity of $\beta$-arrestins is a limiting factor determining endocytic regulation of GPCRs in relevant CNS neurons. This conclusion, in addition to its specific relevance to opioid regulation, suggests a general principle that may underlie regulation between diverse GPCR-mediated signaling processes occurring simultaneously in the same neurons.

It is likely that the ability of NK1R activation to alter morphine's endocytic activity can persist even in the absence of continuous substance $\mathrm{P}$ release. Recycling of NK1Rs is reported to be slow in various cell types (Grady et al., 1995, 1996; Wang and Marvizón, 2002). Dissociation of the $\beta$-arrestin-receptor complex is dependent on dephosphorylation of receptors in endosomes and important for resensitization 
of internalized NK1Rs (Garland et al., 1996). Prolonged retention of $\beta$-arrestins on endosomes, together with slow recycling of NK1Rs, could thus result in low cytoplasmic levels of this regulatory protein after an initial round of receptor activation. In addition, the lack of MOR desensitization as a result of inhibiting endocytosis alters the normal signaling response to drugs such as morphine. Thus, it is possible that the NK1R-mediated regulation of MOR endocytosis, in addition to its acute trafficking effects, contributes to longer-term plasticity in the regulatory profile of opioid drugs.

We were surprised to find a lack of overlap in MOR and NK1R expression on our dissociated striatal culture preparation. It is possible that this reflects developmental differences between our cultures (which are derived from embryonic rats) and adult animals used in previous studies (Pickel et al., 2000; Jabourian et al., 2005). However, we did observe that MORs and NK1Rs are coexpressed in a significant fraction of cultured amygdala neurons. This brain region is known to be important for mediating conditioned reward processes, expresses both MOR and NK1R, and ablation of NK1Rs in these neurons has previously been reported to reduce morphine reward behavior (Everitt et al., 1991; Gadd et al., 2003). We also observed substance P-induced heterologous inhibition of MOR internalization in an acute slice preparation of locus ceruleus, using a recently developed method that allowed quantitative assessment of MOR endocytosis (Arttamangkul et al., 2008). In addition to the amygdala, NK1R-expressing neurons in the locus ceruleus may also play a role in morphine-driven behaviors (Nestler et al., 1994) and in opiate withdrawal (Redmond and Krystal, 1984; Rasmussen et al., 1990). Therefore, it is conceivable that the cell-autonomous regulation established in the present study contributes to NK1R-dependent modulation of opiate responses evident from study of NK1R-knock-out animals and animals in which NK1R function is chemically ablated (Gadd et al., 2003). There is also considerable coexpression of MOR and NK1R in the trigeminal dorsal horn (Aicher et al., 2000). Although we did not examine this region in the present study, and NK1Rs are not essential for morphine antinociception in vivo (De Felipe et al., 1998), it is possible that receptor coexpression could confer NK1R-dependent regulation on opioid signaling in these neurons as well.

The observed inhibitory effect of NK1R activation on MOR endocytosis and desensitization in CNS neurons suggests a novel mechanism by which neurokinin signaling may affect opioid responses in multiple brain regions. Important questions for future study include further examination of the effects of cellautonomous regulation on opioid-mediated neurophysiology and investigation into how interaction between these two neurochemical systems affects functional connectivity between other brain regions. For example, the central nucleus of the amygdala receives reciprocal dopaminergic afferents from the ventral tegmental area and is connected to the core of the nucleus accumbens in the striatum (Ungerstedt, 1971; Wallace et al., 1992). It is conceivable, therefore, that the ability of other GPCRs to alter the trafficking and signaling properties of MORs in response to opiates could have profound effects on neural circuits driving reward behavior. By establishing cell-autonomous regulation of MOR by NK1R activation in several neuronal populations, the present study identifies a new principle by which diverse GPCR-linked signaling systems may be coordinately regulated in the CNS.

\section{References}

Aicher SA, Punnoose A, Goldberg A (2000) $\mu$-Opioid receptors often colocalize with the substance $\mathrm{P}$ receptor (NK1) in the trigeminal dorsal horn (2000) J Neurosci 20:4345-4354.

Altman J, Bayer SA (1995) Atlas of prenatal rat brain development. Boca Raton, FL: CRC.

Alvarez VA, Arttamangkul S, Dang V, Salem A, Whistler JL, von Zastrow M, Grandy DK, Williams JT (2002) $\mu$-Opioid receptors: ligand-dependent activation of potassium conductance, desensitization, and internalization. J Neurosci 22:5769-5776.

Arttamangkul S, Quillinan N, Low MJ, von Zastrow M, Pintar J, Williams JT (2008) Differential activation and trafficking of mu-opioid receptors in brain slices. Mol Pharmacol 74:972-979.

Bouvier M (2001) Oligomerization of G-protein-coupled transmitter receptors. Nat Rev Neurosci 2:274-286.

Bushell T, Endoh T, Simen AA, Ren D, Bindokas VP, Miller RJ (2002) Molecular components of tolerance to opiates in single hippocampal neurons. Mol Pharmacol 61:55-64.

Cheeseman HJ, Pinnock RD, Henderson G (1983) Substance P excitation of rat locus coeruleus neurones. Eur J Pharmacol 94:93-99.

De Felipe C, Herrero JF, O’Brien JA, Palmer JA, Doyle CA, Smith AJ, Laird JM, Belmonte C, Cervero F, Hunt SP (1998) Altered nociception, analgesia and aggression in mice lacking the receptor for substance P. Nature 392:394-397.

Evans CJ (2000) Agonist selective mu-opioid receptor trafficking in rat central nervous system. Mol Psychiatry 5:121-124.

Everitt BJ, Morris KA, O’Brien A, Robbins TW (1991) The basolateral amygdala-ventral striatal system and conditioned place preference: further evidence of limbic-striatal interactions underlying reward-related processes. Neuroscience 42:1-18.

Gadd CA, Murtra P, De Felipe C, Hunt SP (2003) Neurokinin-1 receptorexpressing neurons in the amygdala modulate morphine reward and anxiety behaviors in the mouse. J Neurosci 23:8271-8280.

Garland AM, Grady EF, Lovett M, Vigna SR, Frucht MM, Krause JE, Bunnett NW (1996) Mechanisms of desensitization and resensitization of G protein-coupled neurokinin 1 and neurokinin2 receptors. Mol Pharmacol 49:438-446.

Grady EF, Garland AM, Gamp PD, Lovett M, Payan DG, Bunnett NW (1995) Delineation of the endocytic pathway of substance $\mathrm{P}$ and its seven-transmembrane domain NK1 receptor. Mol Biol Cell 6:509-524.

Grady EF, Gamp PD, Jones E, Baluk P, McDonald DM, Payan DG, Bunnett NW (1996) Endocytosis and recycling of neurokinin 1 receptors in enteric neurons. Neuroscience 75:1239-1254.

Gurevich EV, Benovic JL, Gurevich VV (2002) Arrestin2 and arrestin3 are differentially expressed in the rat brain during postnatal development. Neuroscience 109:421-436.

Haberstock-Debic H, Wein M, Barrot M, Colago EE, Rahman Z, Neve RL, Pickel VM, Nestler EJ, von Zastrow M, Svingos AL (2003) Morphine acutely regulates opioid receptor trafficking selectively in dendrites of nucleus accumbens neurons. J Neurosci 23:4324-4332.

Haberstock-Debic H, Kim KA, Yu YJ, von Zastrow M (2005) Morphine promotes rapid, arrestin-dependent endocytosis of $\mu$-opioid receptors in striatal neurons. J Neurosci 25:7847-7857.

Heimer L, Switzer RD, Van Hoesen GW (1982) Ventral striatum and ventral pallidum: components of the motor system? Trends Neurosci 5:83-87.

Jabourian M, Venance L, Bourgoin S, Ozon S, Pérez S, Godeheu G, Glowinski J, Kemel ML (2005) Functional mu opioid receptors are expressed in cholinergic interneurons of the rat dorsal striatum: territorial specificity and diurnal variation. Eur J Neurosci 21:3301-3309.

Keith DE, Murray SR, Zaki PA, Chu PC, Lissin DV, Kang L, Evans CJ, von Zastrow M (1996) Morphine activates opioid receptors without casing their rapid internalization. J Biol Chem 271:19021-19024.

Keith DE, Anton B, Murray SR, Zaki PA, Chu PC, Lissin DV, MonteilletAgius G, Stewart PL, Evans CJ, von Zastrow M (1998) $\mu$-Opioid receptor internalization: opiate drugs have differential effects on a conserved endocytic mechanism in vitro and in the mammalian brain. Mol Pharmacol 53:377-384.

Klein U, Müller C, Chu P, Birnbaumer M, von Zastrow M (2001) Heterologous inhibition of $\mathrm{G}$ protein-coupled receptor endocytosis mediated by receptor-specific trafficking of beta-arrestins. J Biol Chem 276:17442-174227. 
Koch T, Schulz S, Schröder H, Wolf R, Raulf E, Höllt V (1998) Carboxylterminal splicing of the rat $\mathrm{mu}$ opioid receptor modulates agonistmediated internalization and receptor resensitization. J Biol Chem 273:13652-13657.

Lefkowitz RJ, Rajagopal K, Whalen EJ (2006) New roles for beta-arrestins in cell signaling: not just for seven-transmembrane receptors. Mol Cell 24:643-652.

Lopez-Gimenez JF, Vilaró MT, Milligan G (2008) Morphine desensitization, internalization, and down-regulation of the mu opioid receptor is facilitated by serotonin 5-hydroxytryptamine2A receptor coactivation. Mol Pharmacol 74:1278-1291.

Matthes HW, Maldonado R, Simonin F, Valverde O, Slowe S, Kitchen I, Befort K, Dierich A, Le Meur M, Dollé P, Tzavara E, Hanoune J, Roques BP, Kieffer BL (1996) Loss of morphine-induced analgesia, reward effect and withdrawal symptoms in mice lacking the mu-opioid-receptor gene. Nature 383:819-823.

Mundell SJ, Benovic JL (2000) Selective regulation of endogenous G protein-coupled receptors by arrestins in HEK293 cells. J Biol Chem 275:12900-12908.

Murtra P, Sheasby AM, Hunt SP, De Felipe C (2000) Rewarding effects of opiates are absent in mice lacking the receptor for substance P. Nature 405:180-183.

Nakaya Y, Kaneko T, Shigemoto R, Nakanishi S, Mizuno N (1994) Immunohistochemical localization of substance $\mathrm{P}$ receptor in the central nervous system of the adult rat. J Comp Neurol 347:249-274.

Nestler EJ, Alreja M, Aghajanian GK (1994) Molecular and cellular mechanisms of opiate action: studies in the rat locus coeruleus. Brain Res Bull 35:521-528.

Niwa H, Yamamura K, Miyazaki J (1991) Efficient selection for highexpression transfectants with a novel eukaryotic vector. Gene 108:193-199.

Oakley RH, Laporte SA, Holt JA, Barak LS, Caron MG (1999) Association of $\beta$-arrestin with $\mathrm{G}$-protein coupled receptors during clathrin-mediated endocytosis dictates the profile of receptor resensitization. J Biol Chem 274:32248-32257.

Oakley RH, Laporte SA, Holt JA, Barak LS, Caron MG (2001) Molecular determinants underlying the formation of stable intracellular $G$ proteincoupled receptor- $\beta$-arrestin complexes after receptor endocytosis. J Biol Chem 276:19452-19460

Pfeiffer M, Kirscht S, Stumm R, Koch T, Wu D, Laugsch M, Schröder H, Höllt V, Schulz S (2003) Heterodimerization of substance P and mu-opioid receptors regulates receptor trafficking and resensitization. J Biol Chem 278:51630-51637.

Pickel VM, Douglas J, Chan J, Gamp PD, Bunnett NW (2000) NK1 receptor distribution in cholinergic neurons and targets of substance $\mathrm{P}$ terminals in rat nucleus accumbens. J Comp Neurol 423:500-511.

Pologruto TA, Sabatini BL, Svoboda K (2003) ScanImage: flexible software for operating laser scanning microscopes. Biomed Eng Online 2:13.

Poulin JF, Chevalier B, Laforest S, Drolet G (2006) Enkephalinergic affer- ents of the centromedial amygdala in the rat. J Comp Neurol 496:859-876

Qiu Y, Law PY, Loh HH (2003) Mu-opioid receptor desensitization: role of receptor phosphorylation, internalization, and representation. J Biol Chem 278:36733-36739.

Rasmussen K, Beitner-Johnson DB, Krystal JH, Aghajanian GK, Nestler E (1990) Opiate withdrawal and the rat locus coeruleus: behavioral, electrophysiological, and biochemical correlates. J Neurosci 10:2308-2317.

Redmond DE Jr, Krystal JH (1984) Multiple mechanisms of withdrawal from opioid drugs. Annu Rev Neurosci 7:443-478.

Ripley TL, Gadd CA, De Felipe C, Hunt SP, Stephens DN (2002) Lack of self-administration and behavioural sensitisation to morphine, but not cocaine, in mice lacking NK1 receptors. Neuropharmacology 43:1258-1268

Schmidlin F, Déry O, Bunnett NW, Grady EF (2002) Heterologous regulation of trafficking and signaling of $\mathrm{G}$ protein-coupled receptors: betaarrestin-dependent interactions between neurokinin receptors. Proc Nat Acad Sci U S A 99:3324-3329.

Tempel A, Zukin RS (1987) Neuroanatomical patterns of the $\mu, \delta$, and $\kappa$ opioid receptors of rat brain as determined by quantitative in vitro autoradiography. Proc Natl Acad Sci U S A 84:4308-4312.

Trafton JA, Basbaum AI (2004) [d-Ala2,N-MePhe4,Gly-ol5] enkephalininduced internalization of the micro opioid receptor in the spinal cord of morphine tolerant rats. Neuroscience 125:541-543.

Ueda H, Inoue M, Matsumoto T (2001) Protein kinase C-mediated inhibition of $\mu$-opioid receptor internalization and its involvement in the development of acute tolerance to peripheral $\mu$-agonist analgesia. J Neurosci 21:2967-2973.

Ungerstedt U (1971) Stereotaxic mapping of the monoamine pathways in the rat brain. Acta Physiol Scand Suppl 367:1-48.

Ventimiglia R, Lindsay RM (1998) Rat striatal neurons in low-density, serum-free culture. In: Culturing nerve cells, Ed 2 (Banker G, Goslin K, eds), pp 370-393. Cambridge, MA: MIT.

Wallace DM, Magnuson DJ, Gray TS (1992) Organization of amygdaloid projections to brainstem dopaminergic, noradrenergic, and adrenergic cell groups in the rat. Brain Res Bull 28:447-454.

Wang X, Marvizón JC (2002) Time-course of the internalization and recycling of neurokinin 1 receptors in rat dorsal horn neurons. Brain Res 944:239-247.

Whistler JL, von Zastrow M (1998) Morphine-activated opioid receptors elude desensitization by $\beta$-arrestin. Proc Natl Acad Sci USA 95:9914-9919.

Whistler JL, Chuang HH, Chu P, Jan LY, von Zastrow M (1999) Functional dissociation of $\mathrm{mu}$ opioid receptor signaling and endocytosis: implications for the biology of opiate tolerance and addiction. Neuron 23:737-746.

Zhang J, Ferguson SS, Barak LS, Bodduluri SR, Laporte SA, Law PY, Caron MG (1998) Role for G-protein-coupled receptor kinase in agonistspecific regulation of mu-opioid receptor responsiveness. Proc Natl Acad Sci U S A 95:7157-7162. 